\title{
Histone Modifications at Gene Promoter Regions in Rat Hippocampus after Acute and Chronic Electroconvulsive Seizures
}

\author{
Nadia M. Tsankova, Arvind Kumar, and Eric J. Nestler \\ Department of Psychiatry and Center for Basic Neuroscience, The University of Texas Southwestern Medical Center, Dallas, Texas 75390-9070
}

\begin{abstract}
The mechanism of action of electroconvulsive seizures (ECS), one of the most effective treatments of major depression, may involve the regulation of gene expression. Chromatin remodeling at gene promoter regions is increasingly recognized as a key control point of gene expression and may, therefore, partly mediate acute and chronic effects of ECS on gene activity. Here, we assayed how posttranslational modifications of histones, a major form of chromatin remodeling, are altered at several gene promoters in rat hippocampus at $30 \mathrm{~min}, 2$ $\mathrm{hr}$, and $24 \mathrm{hr}$ after acute or repeated ECS. We performed chromatin immunoprecipitation assays to measure levels of histone $\mathrm{H} 3$ and $\mathrm{H} 4$ acetylation and phosphoacetylation at the promoters of the c- $f \circ s, B D N F$, and $C R E B$ (cAMP response element-binding protein) genes, the expression of which is altered by ECS. We found that, with few exceptions, levels of $\mathrm{H} 4$ acetylation correlated with mRNA levels for c-fos, $B D N F$, and $C R E B$ throughout the acute and chronic time course study, whereas acetylation and phosphoacetylation of $\mathrm{H} 3$ were detected more selectively. Our findings suggest that the chronic downregulation of c-fos transcription, observed in this study, may be achieved at the level of $\mathrm{H} 4$ acetylation, whereas chronic upregulation of $B D N F$ transcription may be sustained via control of $\mathrm{H} 3$ acetylation, selectively at the BDNF P3 and P4 promoters. These data provide the first in vivo demonstration of the involvement of chromatin remodeling in ECS-induced regulation of gene expression in the brain and will help in understanding the mechanisms underlying the efficacy of ECS in the treatment of depression.
\end{abstract}

Key words: chromatin remodeling; histones; electroconvulsive seizure; gene regulation; hippocampus; depression

\section{Introduction}

Chromatin remodeling is a dynamic process that modulates gene expression in dividing as well as non-dividing cells, such as neurons (Guan et al., 2002; Huang et al., 2002; Crosio et al., 2003). Histone modification represents one prominent form of chromatin remodeling. According to the "histone code theory," different modifications of histones at a particular promoter region, alone or in combination, define a specific epigenetic state that encodes gene activation versus gene silencing (Jenuwein and Allis, 2001). Acetylation of histones loosens the structural interactions between DNA and histones, allowing the transcriptional machinery access to the promoters of particular genes. Hyperacetylation at promoters indicates an increase in gene activity, whereas hypoacetylation marks a decrease in activity (for review, see Grunstein, 1997). Acetylation at multiple lysine residues on the N-terminal tail of histone $\mathrm{H} 4$, as well as acetylation at Lys9 and Lys 14 on histone $\mathrm{H} 3$, are common modifications enriched at transcriptionally active genes (Turner, 2002). Furthermore,

\footnotetext{
Received Feb. 18, 2004; revised May 4, 2004; accepted May 11, 2004.

This work was supported by grants from the National Institute of Mental Health and National Institute on Drug Addiction.

Correspondence should be addressed to Dr. Eric J. Nestler, Department of Psychiatry and Center for Basic Neuroscience, The University of Texas Southwestern Medical Center, 5323 Harry Hines Boulevard, Dallas, TX 75390-9070. E-mail: eric.nestler@utsouthwestern.edu.

DOI:10.1523/JNEUROSCI.0589-04.2004

Copyright $\odot 2004$ Society for Neuroscience $\quad 0270-6474 / 04 / 245603-08 \$ 15.00 / 0$
}

Ser10 phosphorylation of $\mathrm{H} 3$ is synergistically coupled with its acetylation at Lys14 (Cheung et al., 2000).

Here, we examined how acute or chronic electroconvulsive seizures (ECS) alter these histone modifications in the hippocampus, a brain region implicated in the pathophysiology of depression in humans and in models of depression in animals (Duman et al., 1997; Manji et al., 2001; Nestler et al., 2002). Acute seizures increase neuronal activity and stimulate the expression of numerous genes, including the immediate-early gene $\mathrm{c}-f o s$ and $B D N F$. Levels of c-fos mRNA peak within minutes, whereas levels of $B D N F$ mRNA peak a few hours after the onset of ECS, but both increases are transient (Morgan et al., 1987; Nibuya et al., 1995). Repeated administration of ECS is one of the most effective treatments of depression, but the molecular mechanisms underlying its clinical effects are incompletely understood (Duman et al., 1997; Hiroi et al., 1998; Chen et al., 2000; Manji et al., 2001; D’Sa and Duman, 2002; Nestler et al., 2002). Several molecules, however, have been implicated to play a role in chronic ECS action, including BDNF and the transcription factor CREB (cAMPresponse element binding protein). Levels of BDNF and CREB are upregulated in the hippocampus by chronic ECS (Nibuya et al., 1995, 1996), effects directly linked to antidepressant activity in animal models (Chen et al., 2001; Shirayama et al., 2002). Furthermore, chronic ECS causes a long-term downregulation of c-fos mRNA levels (Winston et al., 1990).

One way ECS could induce long-term changes in the expres- 
sion of particular genes is through alterations in histone modifications at the promoter regions of these genes. This study provides the first endeavor to characterize such chromatin modifications in the brain after acute and chronic ECS. Using chromatin immunoprecipitation (ChIP) assays, we measured levels of $\mathrm{H} 4$ acetylation, $\mathrm{H} 3$ acetylation, and $\mathrm{H} 3$ phosphoacetylation at the c-fos, $B D N F$, and $C R E B$ promoters in the hippocampus of rats at $30 \mathrm{~min}, 2 \mathrm{hr}$, and $24 \mathrm{hr}$ after an acute or repeated ECS. Our data indicate complex, time-dependent changes in histone modifications at these promoters, which provide new insight into the mechanisms governing ECS-induced regulation of gene expression in the brain.

\section{Materials and Methods}

ECS treatment. Adult male Sprague Dawley rats, 250-275 gm, received a single ECS via ear-clip electrodes (acute group) or daily ECS for $7 \mathrm{~d}$ (chronic group) between 11:00 A.M. and 12:00 P.M. each day (ECS frequency, 100 pulses/sec; pulse width, $0.5 \mathrm{msec}$; shock duration, $0.5 \mathrm{sec}$; current, $50 \mathrm{~mA}$ ). Control animals received sham treatments: they were handled identically to ECS-treated animals but without electrical stimulation. Animals were killed by decapitation $30 \mathrm{~min}, 2 \mathrm{hr}$, or $24 \mathrm{hr}$ after the last seizure.

Chromatin immunoprecipitation assays. Brain tissue was processed into chromatin by use of published protocols (Johnson and Bresnick, 2002; Wells and Farnham, 2002) with some modifications. Whole hippocampus, including subiculum, was removed from decapitated rats by gross dissection, minced to $\sim 1 \mathrm{~mm}$-sized pieces, and immediately crosslinked in 1\% formaldehyde for $15 \mathrm{~min}$ at room temperature. The crosslinking reaction was stopped by adding glycine to a final concentration of $0.125 \mathrm{M}$. The tissue was washed four to six times in cold PBS containing proteinase inhibitors ( $1 \mathrm{~mm}$ PMSF, $1 \mu \mathrm{g} / \mathrm{ml}$ apoprotin, and $1 \mu \mathrm{g} / \mathrm{ml}$ pepstatin A) and then frozen on dry ice.

The chromatin was solubilized and extracted by detergent lysis, followed by sonication. First, minced, fixed hippocampal tissue was homogenized twice, for $10 \mathrm{sec}$, in a cell lysis buffer $(10 \mathrm{~mm}$ Tris, $10 \mathrm{~mm}$ $\mathrm{NaCl}$, and $0.2 \% \mathrm{NP}-40$ ). The homogenate was centrifuged at $5500 \times g$ for $5 \mathrm{~min}$. The supernatant, containing extracellular debris, was decanted, and the pellet was homogenized two more times, for $10 \mathrm{sec}$, using nuclear lysis buffer (ChIP kit number 17-295; Upstate Biotechnology, Lake Placid, NY). Next, the extracted chromatin was sheared to 400-600 bp using the Sonic Dismembrator 550 (Fisher, Hampton, NH). Each sample was sonicated five times on ice, $20 \mathrm{sec}$ each, at $25 \%$ of maximum power.

Chromatin immunoprecipitation assays were performed to measure the levels of histone acetylation or phosphoacetylation at various promoter regions. A protocol outlined in the ChIP kit (Upstate Biotechnology) was used, with some modifications. After the chromatin lysate was extracted and properly fragmented to $400-600 \mathrm{bp}$, the optical density of each sample was determined. Equal amounts of chromatin lysate $(60 \mu \mathrm{g})$ were diluted with ChIP dilution buffer (kit number 17-295; Upstate Biotechnology) to a final volume of $1.5 \mathrm{ml}$. One hundred microliters of the pre-immunoprecipitated lysate were saved as "input" for later normalization.

The chromatin solution was pre-cleared with salmon sperm DNA/ protein A-agarose 50\% gel slurry (catalog \#22811; Pierce, Rockford, IL) for $45 \mathrm{~min}$. It was then immunoprecipitated overnight at $4^{\circ} \mathrm{C}$ with $5 \mu \mathrm{g}$ of antibody directed against $\mathrm{H} 3$ acetylated on Lys9 and Lys14 (kit number 06-599), $7 \mu \mathrm{g}$ of antibody directed against $\mathrm{H} 3$ phosphorylated at Ser10 and acetylated at Lys14 (kit number 07-081), and $5 \mu \mathrm{g}$ of antibody directed against $\mathrm{H} 4$ acetylated at Lys5, Lys8, Lys12, and Lys16 (kit number 06-866; Upstate Biotechnology). The specificity of these antibodies in chromatin immunoprecipitation assays has been established (Cheung et al., 2000; Huang et al., 2002). As a control, samples were immunoprecipitated with $5 \mu \mathrm{g}$ nonimmune rabbit IgG (kit number 12-370; Upstate Biotechnology). After immunoprecipitation, the DNA-histone complex was collected with $40 \mu \mathrm{l}$ of salmon sperm DNA/protein A-agarose beads for $2 \mathrm{hr}$. The beads were sequentially washed once with low salt, high salt, and $\mathrm{LiCl}$ and washed twice with $10 \mathrm{~mm}$ Tris ( $\mathrm{pH}$ 8)/1 mM EDTA buffers (kit number 17-295; Upstate Biotechnology). The DNA-histone complex was then eluted from the beads with $500 \mu \mathrm{l}$ of $\mathrm{NaHCO}_{3} / \mathrm{SDS}$ elution buffer. DNA and histones were dissociated at $65^{\circ} \mathrm{C}$ for $4 \mathrm{hr}$ under highsalt conditions. Proteins were digested using proteinase K treatment for 1 $\mathrm{hr}$ at $45^{\circ} \mathrm{C}$. The DNA, associated with acetylated and phosphoacetylated histones, was extracted with phenol/chlorophorm/isoamyl alcohol, precipitated with $100 \%$ ethanol, and finally resuspended in $80 \mu \mathrm{l}$ of PCRgrade water. Most ChIP experiments were performed twice, on two independent tissue samples, for confirmation.

Quantification of DNA by real-time PCR. Levels of specific histone modifications at each gene promoter of interest were determined by measuring the amount of acetylated or phosphoacetylated histoneassociated DNA by quantitative real-time PCR (ABI Prism 7700; Applied Biosystems, Foster City, CA). Specific primers were designed to amplify proximal promoter regions, $<200 \mathrm{bp}$ long. For c-fos, the primers $5^{\prime}-$ TTCTCTGTTCCGCTCATGACGT- $3^{\prime}$ and $5^{\prime}$-CTTCTCAGTTGCTAGCTGCAATCG- $3^{\prime}$ amplified a region 140 bp upstream of the start codon, which contains a TATA box and a cAMP response element (CRE) consensus sequence. The following primers were used to selectively amplify portions of the BDNF $P 1, P 2, P 3$, or $P 4$ promoter: for $B D N F P 1,5^{\prime}$ TGATCATCACTCACGACCACG- $3^{\prime}$ and $5^{\prime}$-CAGCCTCTCTGAGCCAGTTACG-3'; for BDNF P2, 5' -TGAGGATAGGGGTGGAGTTG-3' and $5^{\prime}$-GCAGCAGGAGGAAAAGGTTA- ${ }^{\prime}$; for BDNF P3, 5'-GCGCGGAATTCTGATTCTGGTAAT-3' and 5'-GAGAGGGCTCCACGCTGCCTTGACG-3'; for BDNF P4, 5' -TGCAGGGGAATTAGGGATAC- $3^{\prime}$ and 5'-TCTTCGGTTGAGCTTCGATT-3'. For CREB, the primers 5'-CATTTACTAACCCAGCCACCACA- $3^{\prime}$ and $5^{\prime}$-GGAGGAGCGTTACAAGCCCTAC- $3^{\prime}$ amplified a region of the $C R E B$ promoter at $-100 \mathrm{bp}$. Finally, $\beta$-tubulin (5'-TAGAACCTTCCTGCGGTCGT-3' and 5'-TTTTCTTCTGGGCTGGTCTC-3'), synaptophysin (5'-TCATCTGGTAGAACTGAGCGGTC-3' and 5'-GAGGCTGTGGGTTTTAGAGGAA- $3^{\prime}$ ), and $\boldsymbol{\epsilon}$-globin (5'-TGACCAATAGTCTCGGAGTCCTG-3' and 5'-AGGCTGAAGGCCTGTCCTTT- $3^{\prime}$ ) were used as controls. Input and immunoprecipitated DNA amplification reactions were run in triplicate in the presence of SYBRGreen (Applied Biosystems). Ct values from each sample were obtained using the Sequence Detector 1.1 software. Relative quantification of template was performed as described previously by Chakrabarti et al. (2002) and by the Applied Biosystems manual, with some modifications. Briefly, a $\Delta \mathrm{Ct}$ value representing the difference between control $\mathrm{Ct}$ and experimental $\mathrm{Ct}$ (acute or chronic) was calculated, using the formula: $\Delta C t=$ (Nacute,chronic - Navecontrol) $\times$ Ctavecontrol, where $N$ is the normalized Ct value of $\mathrm{H} 4[\mathrm{Ct}(\mathrm{H} 4) / \mathrm{Ct}$ (Input)] or of $\mathrm{H} 3[\mathrm{Ct}(\mathrm{H} 3) / \mathrm{Ct}$ (Input)], Nave is the mean $\mathrm{N}$ value for the control, and Ctave is the mean Ct value for the control. Fold differences (acute or chronic ChIP relative to control ChIP) were then determined by raising 2 to the $\Delta \mathrm{Ct}$ power. Mean and SEM values were determined for each fold difference, and these values were used in two-tailed paired $t$ tests (which were adjusted for multiple comparisons) to determine statistical significance $(p<0.05)$. Each PCR reaction, run in triplicate for each brain sample, was repeated at least two independent times.

Measuring $m R N A$ levels by RT-PCR. The whole hippocampus of rats receiving acute or chronic ECS treatments was collected for RNA quantification. RNA was extracted using Trizol reagent from RNA STAT-60 and precipitated with isopropanol. The purified RNA was DNase treated (Ambion, Austin, TX). mRNA was reverse transcribed to cDNA using a first-strand synthesis kit (Invitrogen, Carlsbad, CA). The amount of cDNA was also quantified using real-time PCR. The following primers were used to amplify specific cDNA regions of the transcripts of interest: c-fos (5'-GGAATTAACCTGGTGCTGGA- $3^{\prime}$ and $5^{\prime}$-TGAACATGGACGCTGAAGAG- $\left.3^{\prime}\right)$, BDNF (total) (5'-CCATAAGGACGCGGACTTGTAC- $3^{\prime}$ and $5^{\prime}$-AGACATGTTTGCGGCATCCAGG-3'), CREB (5'-AGTGACTGAGGAGCTTGTACCA- ${ }^{\prime}$ and $5^{\prime}$-TGTGGCTGGGCTTGAAC-3'), and glyceraldehyde-3-phosphate dehydrogenase (GAPDH) (5'AACGACCCCTTCATTGAC-3' and 5'-TCCACGACATACTCAGCAC$\left.3^{\prime}\right)$. Primers for $B D N F$ exons $I-I V$, driven by promoters $P 1$ through $P 4$, respectively, were used as described previously (Tao et al., 1998). GAPDH quantification was used as an internal control for normalization. Fold differences of mRNA levels over control values were calculated using the $\Delta \mathrm{Ct}$ method as described previously (Applied Biosystems manual). PCR reactions were repeated at least two independent times. 
A

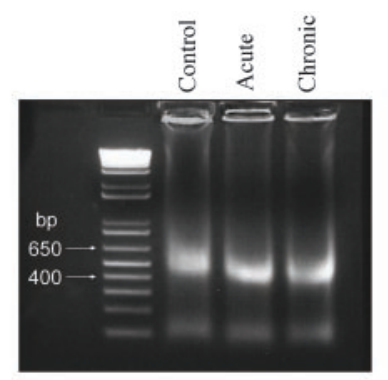

B

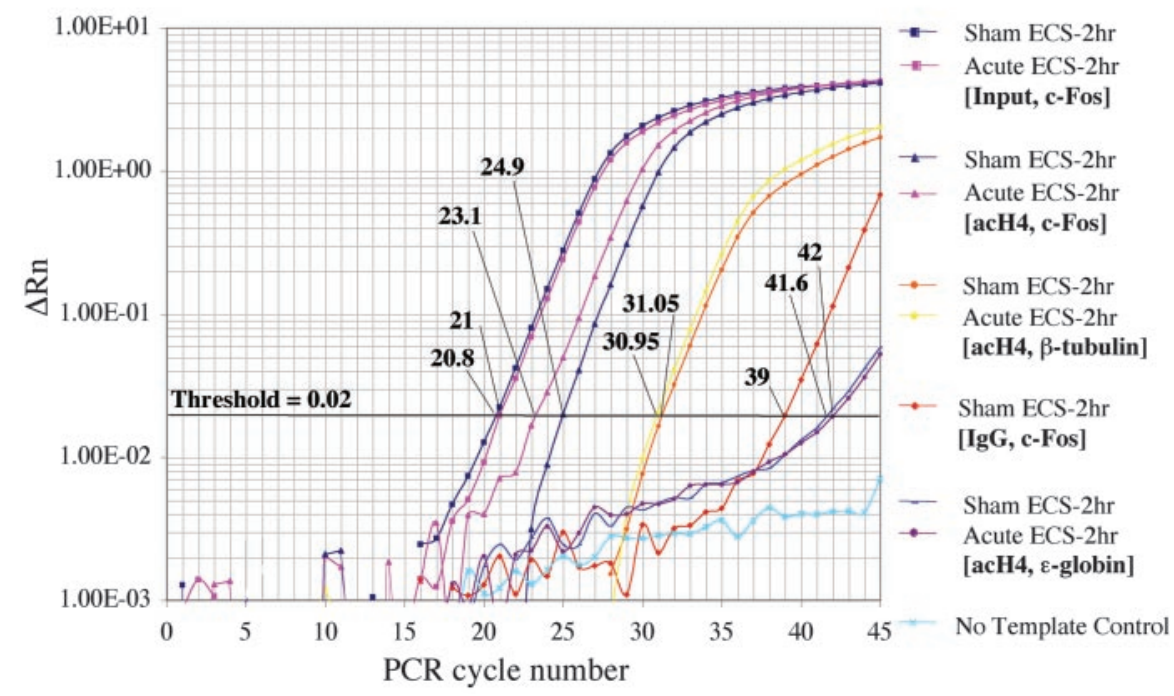

Figure 1. Representative steps in the chromatin immunoprecipitation assay used to measure histone modifications in the hippocampus of ECS-treated and control rats. A, Chromatin was sonicated to fragments of $400-600 \mathrm{bp}$ in size and run on a $2 \%$ agarose gel. Ethidium bromide staining of a resulting, representative gel is shown. $B$, Levels of acetylated $\mathrm{H} 4$ at various gene promoters in the hippocampus were quantified using real-time $P C R$, by comparing relative $\mathrm{Ct}$ values for the various genes of interest at a threshold of 0.02 . (Parallel experiments, not shown, were performed for acetylated and phosphoacetylated $\mathrm{H} 3$. ) $\mathrm{Ct}$ values of immunoprecipitated samples (Control and Acute ECS-2 hr with antibody specific for acetylated $\mathrm{H} 4$ and PCR amplified at the c-fos gene promoter) were normalized to Ct values obtained from "Input," or non-immunoprecipitated genomic DNA, at which there is no difference between acute ECS and control samples, as expected. Comparison of these $\mathrm{Ct}$ values revealed a 3.5-fold increase in levels of $\mathrm{H} 4$ acetylation at the c-fos gene in acute ECS versus control (Sham ECS) samples. In aliquots of the same samples, Ct values from the $\beta$-tubulin gene differed by a negligible 0.1 , reflecting no regulation by acute ECS. Immunoprecipitation with nonimmune lgG yielded much higher $C t$ values, typically 16 cycles higher, indicating a $\sim 65,000$-fold difference (i.e., negligible precipitation of the c-fos gene in the absence of specific antibody). Finally, analysis of $\epsilon$-globin, a gene that is silenced in adult animals and contained within transcriptionally inactive heterochromatin, reveals virtually nondetectable levels of $\mathrm{H} 4$ acetylation.

\section{Results}

Quantification of histone modifications by chromatin immunoprecipitation assays

To better understand the molecular actions of ECS, we studied the histone architecture at the promoter regions of the c-fos, BDNF, and CREB genes in the hippocampus after acute or repeated ECS. Because chromatin remodeling is a dynamic process, we studied histone modifications at these promoters at several different time points ( $30 \mathrm{~min}, 2 \mathrm{hr}$, and $24 \mathrm{hr}$ after acute ECS and 2 and $24 \mathrm{hr}$ after chronic ECS) to clearly differentiate between acute and chronic ECS effects. At these time points, the hippocampus was extracted, minced, and fixed in 1\% formaldehyde to cross-link proteins bound to DNA in vivo. The cross-linked chromatin was then sheared to fragments of $\sim 500 \mathrm{bp}$ in length via vigorous sonication (Fig. $1 A$ ). We then performed chromatin immunoprecipitation assays with antibodies against polyacetylated $\mathrm{H} 4(\mathrm{acH} 4)$, acetylated $\mathrm{H} 3(\mathrm{acH} 3)$, or phosphoacetylated $\mathrm{H} 3$ $(\mathrm{p} / \mathrm{acH} 3)$ and quantified the amount of DNA associated with the modified histones using real-time PCR.
Several controls were performed to confirm the specificity and validity of our assays. To control for the specificity of antibody binding, we immunoprecipitated chromatin samples with nonimmune IgG, which precipitated negligible levels of the various genes studied (Fig. $1 B$ ). To ensure that our technique allowed us to measure acetylation of histones only at promoter regions in the genome where acetylation was present in vivo (i.e., active genes), we confirmed that acetylation was absent in hippocampal tissue at transcriptionally silenced genes, such as the $\epsilon$-globin gene, which is inactivated within neurons early in development (Fig. 1B). Finally, we measured levels of histone acetylation in the hippocampus at the promoters of the $\beta$-tubulin and synaptophysin genes, which are expressed in adult hippocampus but with expression levels that are reportedly unchanged in this region after ECS (Chen et al., 2001; Newton et al., 2003). Indeed, levels of histone modifications at these loci did not differ between control and ECS-treated animals (Figs. $1 \mathrm{~B}, 2$ ). These findings indicate that the observed changes in histones at the c-fos, BDNF, and CREB genes, which are presented below, are not global but are rather limited to genes with expression that varies as a result of ECS treatment.

\section{Histone modifications at the c-fos promoter}

We first assayed histone modifications at the c-fos promoter after acute and chronic ECS. We found that $\mathrm{H} 4$ acetylation at the c-fos promoter in hippocampus increases more than threefold over control values as soon as $30 \mathrm{~min}$ after an acute ECS (Figs. 2, $3 A$; Table 1). This finding was not surprising, given that c-fos is an immediate-early gene that is activated within minutes of neuronal stimulation. In fact, seizures have been shown to induce the rapid and transient increase in c-fos mRNA levels in the hippocampus, peaking $45 \mathrm{~min}$ after seizure onset (Morgan et al., 1987). At $2 \mathrm{hr}$ after an acute ECS, H4 acetylation at the c-fos promoter was still approximately threefold higher compared with control animals. In addition, we were able to detect a 3.7-fold increase in phosphoacetylated $\mathrm{H} 3$ at this time point. By $24 \mathrm{hr}$, the level of $\mathrm{H} 4$ acetylation had returned to control, and the level of $\mathrm{H} 3$ phosphoacetylation was decreased below the level of detection. Levels of acetylated H3 (i.e., H3 acetylation without concomitant phosphorylation) were assayed as well. We did not find any statistically significant changes in $\mathrm{H} 3$ acetylation at the c-fos promoter $30 \mathrm{~min}, 2 \mathrm{hr}$, or $24 \mathrm{hr}$ after acute ECS, although this measure was highly variable for c-fos.

Chronic ECS generally elicited similar histone modifications at the c-fos promoter in the hippocampus. Levels of $\mathrm{H} 4$ acetylation and $\mathrm{H} 3$ phosphoacetylation were both increased $2 \mathrm{hr}$ after chronic ECS, and measures of $\mathrm{H} 3$ acetylation were highly variable. However, one prominent difference between the acute and chronic setting was observed: levels of $\mathrm{H} 4$ acetylation were signif- 


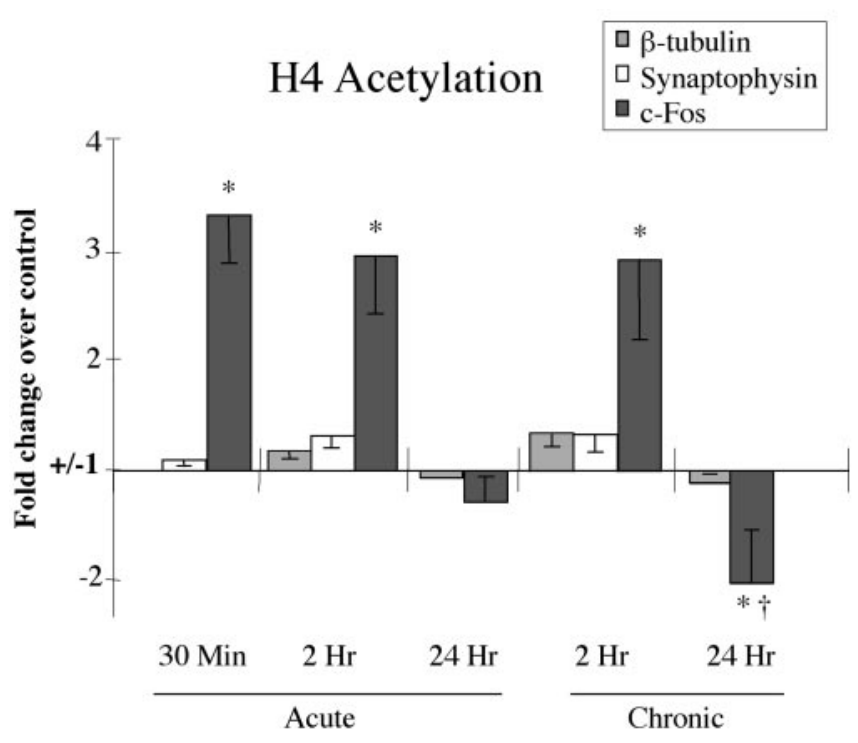

Time after ECS treatment

Figure 2. Regulation of $\mathrm{H} 4$ acetylation at gene promoters after acute or chronic ECS. Levels of $\mathrm{H} 4$ acetylation at the synaptophysin and $\beta$-tubulin promoters, two genes with expression that is not regulated by ECS, are compared with the levels of $\mathrm{H} 4$ acetylation at the $c$-fos promoter at $30 \mathrm{~min}, 2 \mathrm{hr}$, and $24 \mathrm{hr}$ after acute or chronic ECS. Note the robust, time-dependent regulation of $\mathrm{H} 4$ acetylation at the c-fos promoter, but lack of regulation at the synaptophysin and $\beta$-tubulin promoters, under these conditions. Data are expressed as means \pm SEM $(n=4-6$ in each treatment group). Control (sham-ECS) values are $1 \pm$ the following SEMs: 0.02 ( $c$-fos, 30 min), 0.05 (c-fos, $2 \mathrm{hr}$ ), 0.04 (c-fos, $24 \mathrm{hr}$ ), 0.04 ( $\beta$-tubulin, $2 \mathrm{hr}$ ), 0.06 ( $\beta$-tubulin, $24 \mathrm{hr}$ ), 0.05 (synaptophysin, $30 \mathrm{~min}$ ), and 0.03 (synaptophysin, $2 \mathrm{hr}$ ). ${ }^{*} p<0.05$, different from control; $t p<0.05$, different from acute ECS- $24 \mathrm{hr}$, by $t$ test.

icantly decreased $24 \mathrm{hr}$ after chronic ECS, an effect not observed in the acute situation (Figs. 2, 3A; Table 1). Given the previous report that chronic ECS desensitizes the c-fos gene in the hippocampus (Winston et al., 1990), the reduction we observed in $\mathrm{H} 4$ acetylation after chronic ECS conditions implicates this step of chromatin remodeling as a feature of the desensitization process.

To test the degree to which $\mathrm{H} 4$ acetylation correlates with the transcriptional activity of the c-fos gene, we measured c-fos mRNA levels in the hippocampus after acute or chronic ECS. Levels of c-fos mRNA were quantified using real-time PCR and normalized to GAPDH mRNA levels that were unaffected by ECS treatments (data not shown). As reported previously (Morgan et al., 1987), c-fos mRNA expression was dramatically (30-fold) induced 30 min after an acute ECS, remained elevated (15-fold) at $2 \mathrm{hr}$, and returned to control values by $24 \mathrm{hr}$ (Fig. $3 A$; Table 1 ). In contrast, 24 hr after chronic ECS, mRNA levels were significantly decreased to $\sim 60 \%$ of control levels. These results replicate downregulation of c-fos transcription after chronic ECS (Winston et al., 1990). In addition, the results provide additional evidence that, for the c-fos gene, levels of $\mathrm{H} 4$ acetylation correlate with levels of transcription, whereas no such general correlation was apparent between c-fos transcription and levels of $\mathrm{H} 3$ phosphoacetylation or acetylation. It is important to emphasize, of course, that these are correlations only and that causal relationships between histone modification and gene expression in the brain in vivo will require additional investigation.

\section{Histone modifications at the $B D N F$ promoters}

We next examined how histone modifications are altered in the hippocampus by acute and chronic ECS at the BDNF gene, which has been directly implicated in the antidepressant actions of this treatment (see above). We first examined how histone modifications are altered at the BDNF $P 2$ promoter, one of four $B D N F$ promoters $(P 1$ through $P 4)$ that can differentially regulate $B D N F$ expression in the rat brain (Metsis et al., 1993). Each promoter drives the expression of a distinct mRNA, although each transcript encodes an identical BDNF protein. Compared with the other BDNF promoters, $P 2$ shows the most prominent increase in $\mathrm{H} 4$ acetylation in the hippocampus after an acute episode of pilocarpine-induced seizure (Huang et al., 2002), suggesting that acute ECS might similarly increase histone acetylation preferentially at this BDNF promoter. Thirty minutes after an acute ECS, we did not detect any significant change in $\mathrm{H} 4$ acetylation, $\mathrm{H} 3$ acetylation, or $\mathrm{H} 3$ phosphoacetylation at the $P 2$ promoter (Fig. 4; Table 1). Levels of total BDNF mRNA were increased at this time point, but only by 1.8-fold. Two hours after acute ECS, however, we detected an almost threefold increase in $\mathrm{H} 4$ acetylation but no change in $\mathrm{H} 3$ acetylation or phosphoacetylation. The increase in $\mathrm{H} 4$ acetylation at the $P 2$ promoter $2 \mathrm{hr}$ after acute ECS correlates with the nearly fivefold increase we observed in total BDNF mRNA levels at this time point. This induction of BDNF mRNA expression in the hippocampus is consistent with previous findings (Nibuya et al., 1995). Twenty-four hours after acute ECS, when total BDNF mRNA levels had returned to control values, levels of $\mathrm{H} 4$ acetylation at the $\mathrm{P} 2$ promoter had partially recovered toward control levels as well.

Examination of the effects of chronic ECS revealed several dramatic shifts in the regulation of histone modifications at the $B D N F$ gene (Fig. 4; Table 1). Again, focusing on the BDNF P2 promoter, levels of $\mathrm{H} 3$ acetylation and phosphoacetylation were increased $2 \mathrm{hr}$ after chronic ECS, whereas they were not affected by acute ECS at this time point. By $24 \mathrm{hr}$ after chronic ECS, however, these modifications no longer showed a significant change over control levels. Furthermore, although levels of H4 acetylation at the $P 2$ promoter were induced $2 \mathrm{hr}$ after chronic ECS (as seen also for the acute situation), by $24 \mathrm{hr}$ levels of H4 acetylation were dramatically (approximately fourfold) decreased. This decrease did not correlate with the sustained approximate twofold increase in total BDNF mRNA levels we observed $24 \mathrm{hr}$ after chronic ECS administration. This dissociation prompted us to (1) measure the mRNA levels driven by each distinct BDNF promoter and (2) to study how ECS affects the histone architecture at the other BDNF promoters $(P 1, P 3$, and $P 4)$, particularly under chronic treatment conditions.

Quantitative RT-PCR analysis of BDNF mRNA driven by the $P 1$ through $P 4$ promoters revealed that $30 \mathrm{~min}$ and $2 \mathrm{hr}$ after acute ECS the mRNA levels of all four splice variants were significantly upregulated (data not shown). These data confirm previous studies of the promoter-specific regulation of BDNF mRNA after acute ECS or kainic acid treatments (Metsis et al., 1993; Dias et al., 2003). Chronic ECS, however, showed more restricted BDNF upregulation. Although $B D N F$ mRNA driven by the $P 1, P 2$, or $P 3$ promoter was not significantly increased $24 \mathrm{hr}$ after chronic ECS, $B D N F$ mRNA driven by $P 4$ showed a sustained twofold increase, which was highly significant $(209 \pm 29 \%$ of control \pm SEM; $n=4$; $p<0.05)$. This suggests that the increase in total BDNF mRNA levels seen $24 \mathrm{hr}$ after chronic ECS treatment is attributable to the selective activation of the BDNF P4 promoter.

Next, we examined changes in histone modifications at the $B D N F$ P1, P3, and P4 promoters after acute or chronic ECS and compared these changes with our mRNA data. In contrast to the observed increase in $\mathrm{H} 4$ acetylation at the BDNF $\mathrm{P} 2$ promoter after acute ECS, there were no changes in $\mathrm{H} 4$ acetylation, but 
A

c-Fos

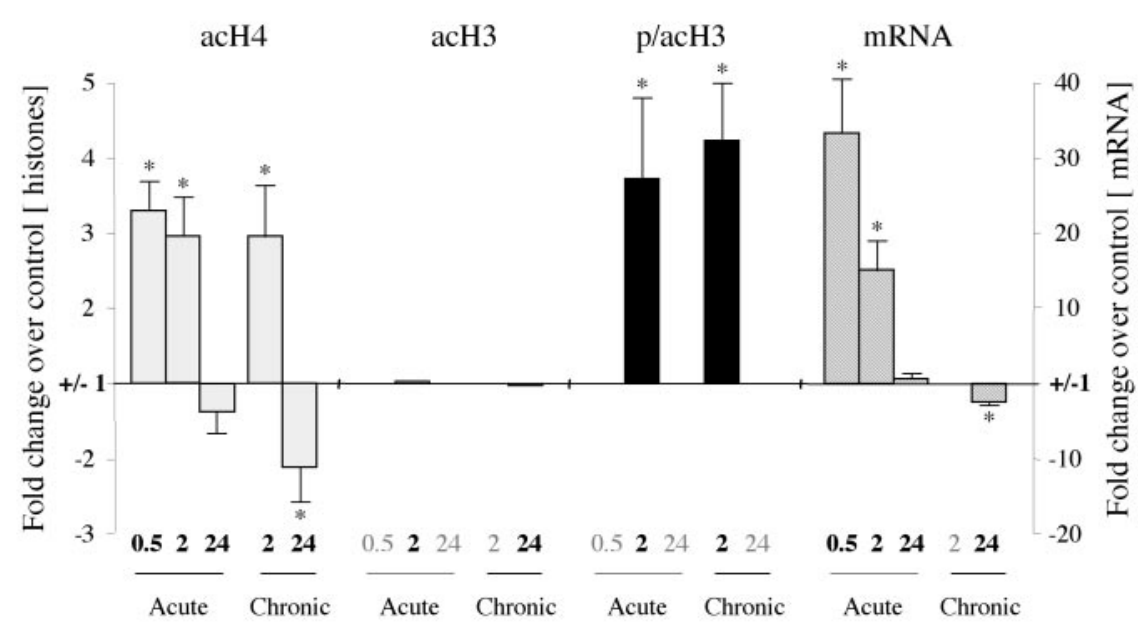

Time after ECS (hr)

B

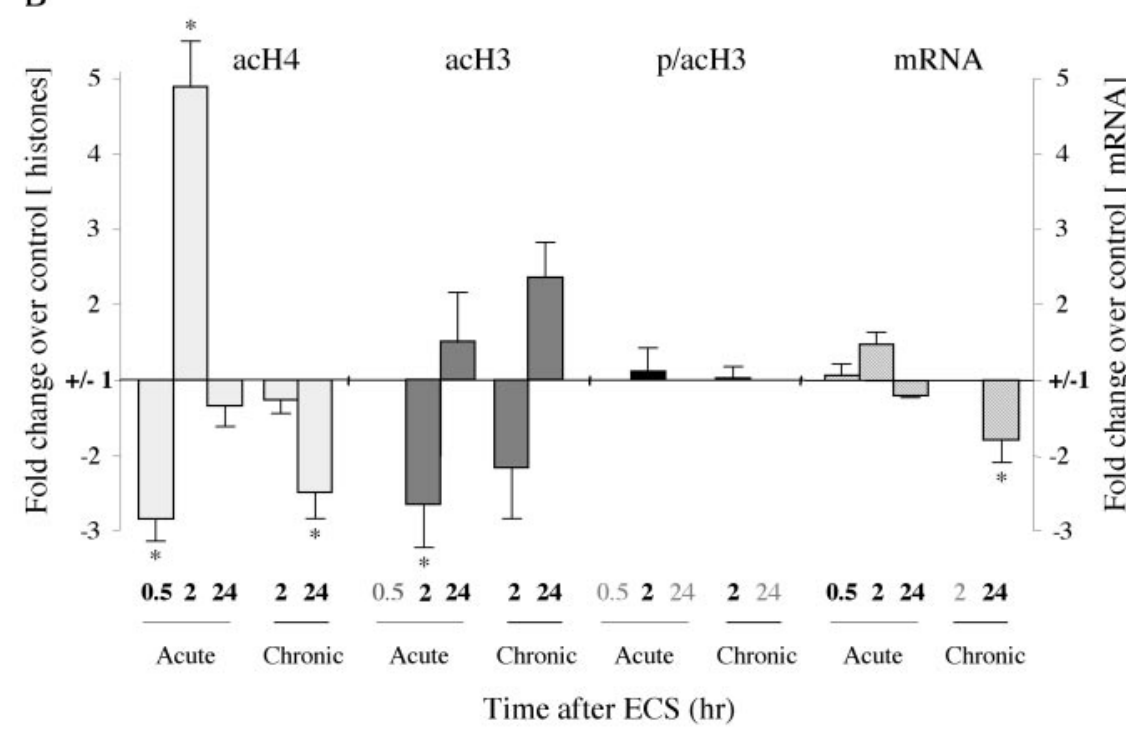

Figure 3. Patterns of histone modifications after acute or chronic ECS at the $c$-fos and CREB promoters. Levels of mRNA for these genes were measured as well. Changes in histone modifications and mRNA are represented as mean \pm SEM of fold change over control (control, $1 \pm$ SEM; $n=4-6 ;{ }^{*} p<0.05$ from control). Values with large variability (in Table 1 , indicated by ${ }^{d}$ ) are not depicted; these data points (data not shown) correspond to the time points written in gray. Table 1 presents all of the data in quantitative form. $A$, Changes at the c-fos promoter. At 30 min after an acute ECS, there was a 3.3-fold increase in $\mathrm{H} 4$ acetylation (acH4) and a 32.4-fold increase in levels of c-fos mRNA. At $2 \mathrm{hr}$ after acute ECS, there was a threefold increase in $\mathrm{H} 4$ acetylation, a 3.7-fold increase in $\mathrm{H} 3$ phosphoacetylation (p/acH3), and a 15.1-fold increase in mRNA levels. At $24 \mathrm{hr}$ after acute ECS, there were no significant changes in histone modifications or c-fos mRNA levels. After chronic ECS, the same histone modifications were observed at $2 \mathrm{hr}$ as seen in the acute situation. However, at $24 \mathrm{hr}$, chronic ECS caused a twofold decrease in $\mathrm{H} 4$ acetylation, which correlated with a 1.8-fold decrease in levels of c-fos mRNA. B, Changes at the CREB promoter. At 30 min after an acute ECS, there was a 2.8-fold decrease in $\mathrm{H} 4$ acetylation, large variability in levels of $\mathrm{H} 3$ acetylation (acH3) and phosphoacetylation, and no change in CREB mRNA levels. At $2 \mathrm{hr}$ after acute ECS, there was a 4.9-fold increase in $\mathrm{H} 4$ acetylation acutely, but a 2.7-fold decrease in $\mathrm{H} 3$ acetylation. CREB mRNA levels showed a trend toward a small (1.5-fold) increase. At $24 \mathrm{hr}$ after acute ECS, no significant changes in histone modifications or CREB mRNA levels were observed. After chronic ECS, the major differences from the acute situation were seen at $24 \mathrm{hr}$, when a 2.5 -fold decrease in $\mathrm{H} 4$ acetylation but a 2.4-fold increase in $\mathrm{H} 3$ acetylation were observed along with a 1.8-fold decrease in CREB mRNA levels.

trends for induction of $\mathrm{H} 3$ acetylation, at the $\mathrm{P} 3$ and $P 4$ promoters (Fig. 4; Table 1). Moreover, these latter promoter regions showed significant chromatin regulation after chronic ECS. In particular, we observed a severalfold increase in $\mathrm{H} 3$ acetylation at the BDNF $P 3$ and $P 4$ promoters $24 \mathrm{hr}$ after chronic ECS, which correlated with the increase in BDNF mRNA levels driven by the $\mathrm{P} 4$ promoter at this time point. $\mathrm{H} 4$ acetylation and $\mathrm{H} 3$ phosphoacetylation did not change significantly at the $P 3$ or $P 4$ promoters $24 \mathrm{hr}$ after chronic ECS.

\section{Histone modifications at the CREB promoter}

CREB is a transcription factor that regulates the expression of many genes and has been implicated directly in the antidepressant effects of ECS treatment in the hippocampus (as mentioned above). Furthermore, CREB is known to regulate the transcription of the c-fos and BDNF genes by binding to CRE sites within their promoters in its active (dimerized, phosphorylated) form. It was, therefore, of particular interest to study histone modifications at the $C R E B$ gene at varying time points after acute or chronic ECS.

We found a significant, approximate threefold decrease in $\mathrm{H} 4$ acetylation at the $C R E B$ gene promoter in the hippocampus 30 min after an acute ECS (Fig. 3B; Table 1). There was no significant change in $\mathrm{H} 3$ acetylation or phosphoacetylation at this time point. Histone modifications at the CREB promoter at $2 \mathrm{hr}$ after acute ECS were more divergent. First, there was a large, fivefold increase in $\mathrm{H} 4$ acetylation relative to control animals. This increase amounted to an eightfold change in $\mathrm{H} 4$ acetylation from $30 \mathrm{~min}$ to $2 \mathrm{hr}$ after acute ECS. In contrast, levels of $\mathrm{H} 3$ acetylation showed a significant 2.7 -fold decrease at 2 $\mathrm{hr}$ after acute ECS. At $24 \mathrm{hr}$ after acute ECS, no parameter of histone modification was significantly affected at the $C R E B$ promoter. We also observed no significant change in CREB mRNA levels at $30 \mathrm{~min}, 2$ $\mathrm{hr}$, or $24 \mathrm{hr}$ after acute ECS, although there was a trend toward a small (50\%) increase in CREB expression at $2 \mathrm{hr}$ (Fig. 3B; Table 1).

A similarly complicated pattern of histone modification at the CREB promoter in the hippocampus was observed after chronic ECS. Chronic ECS no longer increased $\mathrm{H} 4$ acetylation levels at the CREB promoter at the $2 \mathrm{hr}$ time point as seen for acute ECS. In fact, a $\sim 2.5$-fold decrease in H4 acetylation levels were apparent by 24 $\mathrm{hr}$ after chronic ECS. In addition, levels of $\mathrm{H} 3$ acetylation were reduced at $2 \mathrm{hr}$, but increased at $24 \mathrm{hr}$, after chronic ECS. Finally, as seen for most measures, levels of phosphoacetylated $\mathrm{H} 3$ were low and variable and showed no significant regulation by chronic ECS. We also found that chronic ECS causes a small, but significant, decrease in CREB mRNA levels in the hippocampus at $24 \mathrm{hr}$. This was a surprising finding, given the previous report that chronic 
Table 1. Regulation of histone modifications at the c-fos, BDNF, and CREB promoters in the hippocampus by acute and chronic ECS

\begin{tabular}{|c|c|c|c|c|c|c|c|c|}
\hline \multirow[b]{2}{*}{ Promoter/time course } & \multicolumn{2}{|l|}{ c-fos } & \multicolumn{2}{|l|}{ BDNFP2 } & \multicolumn{2}{|l|}{ BDNFP3 } & \multicolumn{2}{|l|}{ CREB } \\
\hline & Acute & Chronic & Acute & Chronic & Acute & Chronic & Acute & Chronic \\
\hline \multicolumn{9}{|l|}{ H4 acetylation } \\
\hline $30 \mathrm{~min}$ & $330 \pm 41^{a}$ & & $-220 \pm 130^{d}$ & & $156 \pm 42$ & & $-283 \pm 30^{b}$ & \\
\hline $2 \mathrm{hr}$ & $295 \pm 53^{a}$ & $298 \pm 71^{a}$ & $278 \pm 60^{a}$ & $268 \pm 50^{a}$ & $114 \pm 23$ & $131 \pm 16$ & $490 \pm 62^{a}$ & $-125 \pm 19$ \\
\hline $24 \mathrm{~h}$ & $-132 \pm 32$ & $-205 \pm 49^{b}$ & $185 \pm 30^{a}$ & $-359 \pm 79^{b}$ & $-139 \pm 51$ & $-138 \pm 14$ & $-134 \pm 32$ & $-246 \pm 37^{b}$ \\
\hline \multicolumn{9}{|l|}{$\mathrm{H} 3$ acetylation } \\
\hline $30 \mathrm{~min}$ & ND & & ND & & $220 \pm 98^{a, c}$ & & $-351 \pm 142^{d}$ & \\
\hline $2 \mathrm{hr}$ & $100 \pm 16$ & $295 \pm 222^{d}$ & $-188 \pm 86^{d}$ & $195 \pm 43^{a}$ & $-133 \pm 15$ & $-123 \pm 11$ & $-265 \pm 60^{b}$ & $-216 \pm 69^{b, c}$ \\
\hline $24 \mathrm{~h}$ & $183 \pm 67^{d}$ & $98 \pm 29$ & ND & & $339 \pm 116^{a, c}$ & $411 \pm 54^{a}$ & $153 \pm 69$ & $236 \pm 47^{a, c}$ \\
\hline \multicolumn{9}{|l|}{ H3 phosphoacetylation } \\
\hline $30 \mathrm{~min}$ & ND & & ND & & $344 \pm 276^{d}$ & & $-239 \pm 117^{d}$ & \\
\hline $2 \mathrm{hr}$ & $372 \pm 110^{a}$ & $424 \pm 82^{a}$ & $130 \pm 47^{d}$ & $290 \pm 39^{a}$ & $154 \pm 53$ & $-148 \pm 24^{b}$ & $113 \pm 31$ & $103 \pm 18$ \\
\hline $24 \mathrm{~h}$ & ND & & ND & & ND & & ND & \\
\hline mRNA levels & & & & (total BDNF) & & & & \\
\hline $30 \mathrm{~min}$ & $3237 \pm 728^{a}$ & & $185 \pm 24^{a}$ & & & & $107 \pm 16$ & \\
\hline $2 \mathrm{hr}$ & $1514 \pm 418^{a}$ & & $482 \pm 44^{a}$ & & & & $149 \pm 19$ & \\
\hline $24 \mathrm{~h}$ & $131 \pm 28$ & $-176 \pm 10^{b}$ & $-123 \pm 11$ & $214 \pm 24^{a}$ & & & $-119 \pm 2$ & $-178 \pm 31^{b}$ \\
\hline
\end{tabular}

This is a comprehensive report of our data, expressed as percentage increase ( $a$ ) or decrease $(b)$ over control \pm SEM ( $n=4-6$ animals in each treatment group). The values shown $(a$ or $b$ ) represent statistically significant changes ( $p<$ 0.05 by paired $t$ test). Percentages (c) indicate trends, changes that did not reach a level of significance (usually because of large variability in the fold increase or the fold decrease among the samples) but in which all samples showed a change in the same direction and were significant by $\chi^{2}$ test. The values shown $(d)$ represent conditions for which there was large variability and hence no apparent regulation by ECS. C $\mathrm{t}$ values were too high in some samples, indicating that the anti-histone antibody precipitated negligible levels of that gene and was therefore not detectable (ND).

${ }^{a}$ Increase in acetylation/phosphoacetylation, $p<0.05$.

${ }^{b}$ Decrease in acetylation/phosphoacetylation, $p<0.05$.

'Trend toward increase or decrease $(-), p<0.1$.

${ }^{d}$ Large variability among samples, no trend for regulation.

ECS increases CREB mRNA expression in this brain region (Nibuya et al., 1996). The explanation for this divergent finding is unknown. One possibility is that Nibuya et al. (1996) had demonstrated increased CREB expression in specific subfields of the hippocampus by in situ hybridization, whereas the regulation of CREB mRNA levels and histone modifications reported here would reflect global changes in these measures throughout the hippocampus.

\section{Discussion}

ECS remains one of the most effective treatments for major depression. Like chemical antidepressants, ECS exerts its clinical effects only after repeated administration, suggesting that longterm adaptations at the level of gene expression might be involved. The goal of the present study was to determine whether some of the genomic effects of ECS could be mediated at the level of chromatin remodeling, which has been shown in recent years to be a major determinant of gene regulation. We studied the effect of acute and chronic ECS on several common posttranslational modifications of histones $\mathrm{H} 3$ and $\mathrm{H} 4$ at three ECSregulated gene promoters: the immediate-early gene c-fos, the neurotrophic factor $B D N F$, and the transcription factor $C R E B$, in the hippocampus. We found that, with few exceptions, levels of $\mathrm{H} 4$ acetylation correlate best with the expression of c-fos, BDNF, and $C R E B$ mRNA levels at several time points after acute and chronic ECS. This important observation supports the hypothesis that histone hyperacetylation is associated with increased levels of gene activity in the brain and proposes that measuring levels of $\mathrm{H} 4$ acetylation at a promoter might serve as a novel marker for the dynamic, in vivo state of the activity of a gene. There are two exceptions to this observed correlation, however, that should be highlighted.

First, levels of $\mathrm{H} 4$ acetylation were not a reliable measure for $C R E B$ expression during acute ECS treatment: we did not observe a significant increase in CREB mRNA levels after acute ECS, although $\mathrm{H} 4$ acetylation increased severalfold at the $C R E B$ promoter under these conditions. One possible explanation for this discrepancy is that other modifications at the $C R E B$ promoter counterbalance the effect of $\mathrm{H} 4$ acetylation. Chromatin remodeling is a dynamic process in which several histones can be modified within close temporal and spatial proximity. As suggested by the histone code hypothesis, a combination of several histone modifications may ultimately determine the outcome of gene expression. In support of this possibility, we observed a significant decrease in $\mathrm{H} 3$ acetylation at the $C R E B$ promoter after an acute ECS.

The second exception to the observed link between $\mathrm{H} 4$ acetylation and transcript levels was noticed at the BDNF $P 2$ promoter $24 \mathrm{hr}$ after chronic ECS, when total BDNF mRNA levels were increased, as reported previously (Nibuya et al., 1995), whereas H4 acetylation was significantly decreased. A likely explanation for this discrepancy is that $B D N F$ transcription is being regulated differently chronically than it is acutely. In support of this, we found that although acute seizure induces all four BDNF promoters, as shown previously (Metsis et al., 1993; Dias et al., 2003), chronic ECS selectively induces the $P 4$ promoter only. Moreover, we showed that among the histone modifications examined, only H3 acetylation showed a significant increase after chronic ECS, and this increase was specific for the $P 4$ and $P 3$ promoters. Recently, $\mathrm{H} 4$ acetylation at the BDNF P2 promoter was shown to increase significantly after an acute episode of pilocarpineinduced seizure, whereas no change was evident at the $P 3$ promoter and a slight decrease was seen at the P4 promoter (Huang et al., 2002). In our study, we have confirmed that acute seizure, in this case ECS, increases $\mathrm{H} 4$ acetylation selectively at the BDNF $\mathrm{P} 2$ promoter. Interestingly, such chromatin remodeling appears to shift toward the $P 3$ and $P 4$ promoters under chronic ECS conditions. It is noteworthy that whereas only BDNF P4 mRNA levels were significantly increased $24 \mathrm{hr}$ after chronic ECS, H3 acetylation was induced at both the $P 4$ and $P 3$ promoters. This increase at $P 3$, in the absence of increased BDNF P3 mRNA levels, could be explained by the fact that the $P 3$ and $P 4$ promoters are only $0.8 \mathrm{~kb}$ apart in the primary $B D N F$ transcript (Timmusk et al., 1993), thus permitting some of the histone enrichments at $P 4$ to also be detected at the $P 3$ promoter. 


\section{BDNF P2}

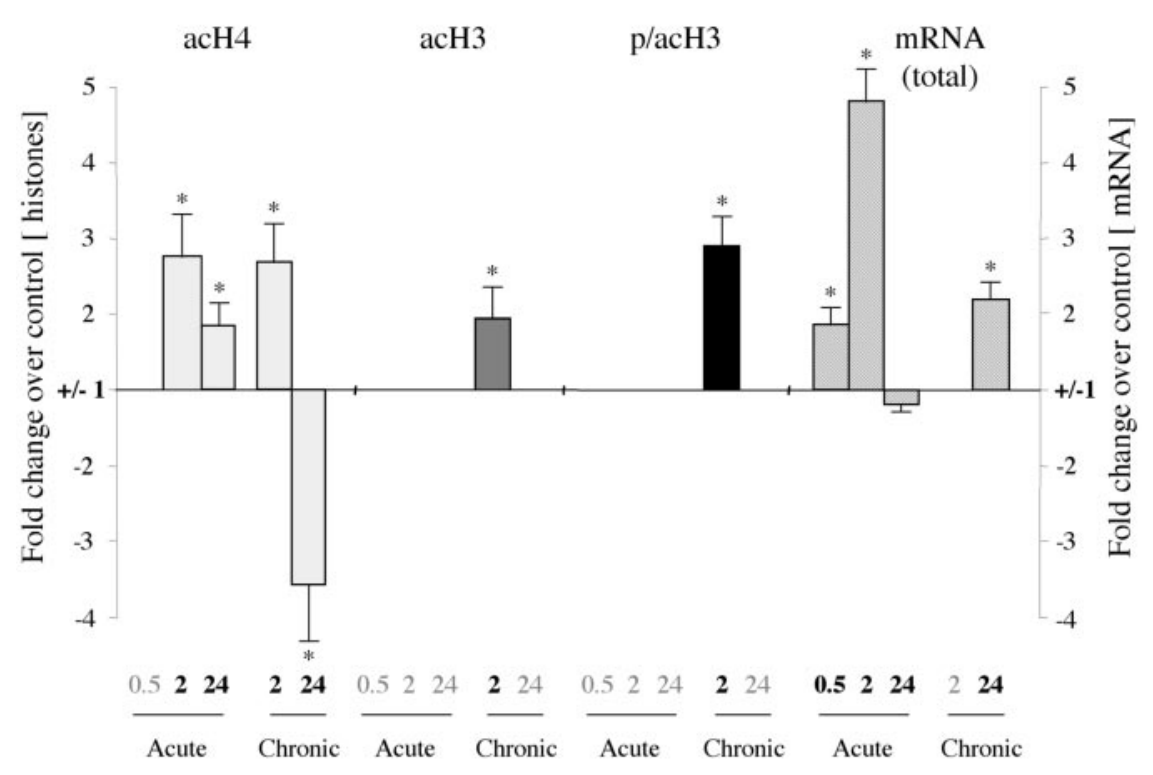

BDNF P3

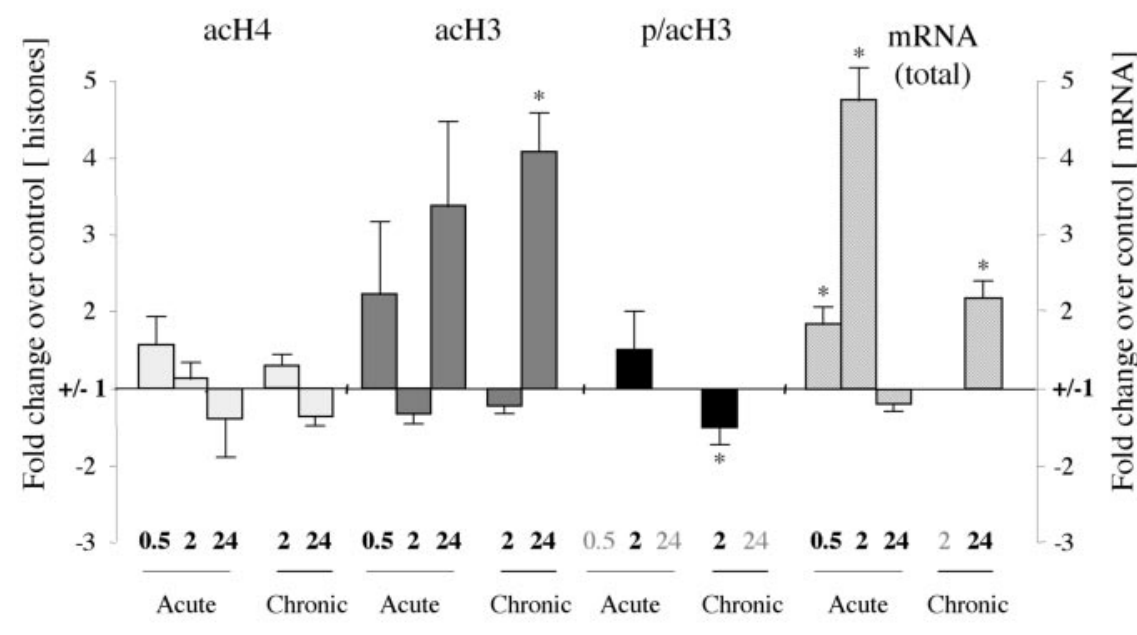

Time after ECS (hr)

Figure 4. Patterns of histone modifications after acute or chronic ECS at the BDNFP2 and $P 3$ promoters. At 30 min after an acute $E C S$, no significant changes in histone modifications were observed at the $P 2$ or $P 3$ promoter, whereas total BDNF mRNA levels were increased by 1.8-fold. At $2 \mathrm{hr}$ after acute $\mathrm{ECS}, \mathrm{H} 4$ acetylation increased 2.8-fold at the $P 2$ promoter, with no changes seen in $\mathrm{H} 3$ at either the $P 2$ or $P 3$ promoters, whereas total BDNF mRNA levels increased by 4.8 -fold. At $24 \mathrm{hr}$ after acute $E C S$, when BDNF mRNA levels had returned to control values, levels of $\mathrm{H} 4$ acetylation were increased 1.9-fold at the $P 2$ promoter, whereas $\mathrm{H} 3$ acetylation tended to increase at the $P 3$ promoter. After chronic ECS, the major differences from the acute situation were seen at $24 \mathrm{hr}$, when a 3.6-fold decrease in $\mathrm{H} 4$ acetylation at the $\mathrm{P} 2$ promoter but a 4.1 -fold increase in $\mathrm{H} 3$ acetylation at the $\mathrm{P} 3$ promoter were observed along with a 2.1-fold increase in total BDNF mRNA levels. In general, the $P 4$ promoter showed similar alterations in histone modifications as seen for the $P 3$ promoter: $2 \mathrm{hr}$ Acute $\mathrm{ECS}$ : $\mathrm{H} 4$ acetylation, $-336 \pm 79 \%(*) ; \mathrm{H} 3$ acetylation, $134 \pm 31 \%$; 24 hr Acute ECS: $\mathrm{H} 4$ acetylation, $-202 \pm 96 \%$; H3 acetylation, $132 \pm 5 \% ; 24$ hr Chronic ECS: $\mathrm{H} 4$ acetylation, $-119 \pm 19 \%$; H3 acetylation, $184 \pm 11 \%\left({ }^{*}\right)\left(n=6-8 ;{ }^{*} p<0.05\right)$.

$\mathrm{H} 3$ acetylation at Lys9 and Lys14, similar to $\mathrm{H} 4$ acetylation, is found in transcriptionally active promoters (Turner, 2002). Our findings suggest that although acetylation of $\mathrm{H} 4$ modulates $B D N F$ expression through the $P 2$ promoter in acute seizure conditions, acetylation of $\mathrm{H} 3$ at the $P 4$ and $P 3$ promoters may be the more important determinant of $B D N F$ expression after chronic ECS. The decrease in $\mathrm{H} 4$ acetylation at the BDNF $P 2$ promoter after chronic ECS could, in fact, indicate that this promoter is being suppressed chronically to allow the other promoters to override control of $B D N F$ expression. Previous studies have proposed a role for $C R E B$ in mediating the sustained induction of $B D N F$ expression in the hippocampus after chronic ECS (Duman et al., 1997; Thome et al., 2000; D'Sa and Duman, 2002). It will be important in future studies to determine whether the induction of $\mathrm{H} 3$ acetylation observed here is related to this CREBdependent mechanism of BDNF gene regulation.

In contrast to the regulation of $\mathrm{H} 4$ acetylation, which was seen at all three genes studied, regulation of $\mathrm{H} 3$ phosphoacetylation was much more restricted. Levels of phosphoacetylated $\mathrm{H} 3$ showed a large increase at the c-fos promoter specifically 2 hr after an acute ECS. A recent study reports that the seizure-inducing drugs pilocarpine and kainic acid induce rapid, transient phosphorylation of $\mathrm{H} 3$ at Ser10 in hippocampal neurons (Crosio et al., 2003). This modification was coupled with $\mathrm{H} 3$ acetylation at nearby Lys14 and was correlated with the activation of the MAP kinase pathway and the induction of $\mathrm{c}$-fos transcription. These and other findings have led to the suggestion that phosphoacetylation of $\mathrm{H} 3$ is the most direct link between signal transduction and histone modification (Cheung et al., 2000; Thomson et al., 2001; Clayton and Mahadevan, 2003; Crosio et al., 2003). Here, we similarly show that acute ECS treatment increases $\mathrm{H} 3$ phosphoacetylation; however, this change was delayed compared with the induction of $\mathrm{H} 4$ acetylation and c-fos mRNA levels. Moreover, the only other significant change in $\mathrm{H} 3$ phosphoacetylation observed in this study was at the BDNF P2 promoter $2 \mathrm{hr}$ after chronic ECS, an effect not observed after acute ECS when BDNF mRNA levels are greatly induced. Therefore, it appears that $\mathrm{H} 3$ phosphoacetylation in vivo occurs transiently at the promoters of some highly reactive genes (i.e., c-fos), but not all such genes (i.e., BDNF). Moreover, some unique changes in $\mathrm{H} 3$ phosphoacetylation may occur after chronic perturbations, such as observed here for BDNF at the P2 promoter. We did not observe a significant change in $\mathrm{H} 3$ phosphoacetylation $24 \mathrm{hr}$ after acute or chronic ECS at either the c-fos or BDNF promoters. This suggests that even if $\mathrm{H} 3$ phosphoacetylation occurs acutely or chronically, it is not a lasting effect.

Chromatin remodeling is normally described as a dynamic process induced by transient histone modifications. However, we observed several chromatin modifications that were changed in chronic ECS conditions and persisted $24 \mathrm{hr}$ after the last seizure. Thus, it is likely that adaptations in chromatin structure exert not 
only short-term, transient effects, but also longer-term effects on gene activity. Specifically, the downregulation of $\mathrm{H} 4$ acetylation at the $\mathrm{c}$-fos and $C R E B$ promoters, and the upregulation of $\mathrm{H} 3$ acetylation at the $B D N F P 3$ and $P 4$ promoters, provide proximal mechanisms by which chronic ECS might alter the expression of these three genes in the hippocampus. Such changes may well play an important role in modulating neuroplasticity in the adult brain. Indeed, the sustained activation of BDNF expression after chronic ECS, which we hypothesize may be mediated in part via $\mathrm{H} 3$ acetylation at the $P 3$ and $P 4$ promoters, could contribute to the antidepressant effects of ECS (Shirayama et al., 2002). Similarly, the sustained inactivation of the c-fos gene after chronic ECS (Winston et al., 1990) may be mediated in part via reduced $\mathrm{H} 4$ acetylation at the promoter of the gene.

The mechanisms by which these sustained changes in histone modifications occur are not known. Chronic ECS-induced changes in histone acetylation could be regulated via recruitment of specific histone deacetylases (HDACs; enzymes that decrease histone acetylation), histone acetyltransferases (HATs; enzymes that increase histone acetylation), or proteins that regulate these enzymes. It is generally believed that HDACs and HATs are controlled mainly at the level of their recruitment to target promoters, but some evidence suggests that at least CREB-binding protein, a type of HAT, may be regulated directly through $\mathrm{Ca}^{2+}$ signaling (West et al., 2002). Our findings demonstrate the importance of better understanding the role of these enzymes and associated proteins and the signaling pathways that regulate them, not only in activity-dependent transcription but also in models relevant for chronic adaptation in the brain.

The results of the present study must be seen as a necessary first step in elucidating the types of changes in histone modifications that occur in the nervous system after acute and chronic ECS. Our findings reveal that acute and chronic ECS cause histone-, time-, and promoter-specific changes in the hippocampus and that some of these modifications are highly correlated with alterations in gene expression observed under these conditions. Additional characterization of these changes in histone modifications will contribute to our understanding of the mechanisms of action of ECS as a leading treatment for severe depression and, more generally, shed light on the molecular mechanisms governing gene regulation in the brain in vivo.

\section{References}

Chakrabarti SK, James JC, Mirmira RG (2002) Quantitative assessment of gene targeting in vitro and in vivo by the pancreatic transcription factor, Pdxl. Importance of chromatin structure in directing promoter binding. J Biol Chem 277:13286-13293.

Chen J, Zhang Y, Kelz MB, Steffen C, Ang ES, Zeng L, Nestler EJ (2000) Induction of cyclin-dependent kinase 5 in the hippocampus by chronic electroconvulsive seizures: role of [Delta]FosB. J Neurosci 20:8965-8971.

Chen J, Sochivko D, Beck H, Marechal D, Wiestler OD, Becker AJ (2001) Activity-induced expression of common reference genes in individual cns neurons. Lab Invest 81:913-916.

Cheung P, Tanner KG, Cheung WL, Sassone-Corsi P, Denu JM, Allis CD (2000) Synergistic coupling of histone $\mathrm{H} 3$ phosphorylation and acetylation in response to epidermal growth factor stimulation. Mol Cell 5:905-915.

Clayton AL, Mahadevan LC (2003) MAP kinase-mediated phosphoacetylation of histone $\mathrm{H} 3$ and inducible gene regulation. FEBS Lett 546:51-58.

Crosio C, Heitz E, Allis CD, Borrelli E, Sassone-Corsi P (2003) Chromatin remodeling and neuronal response: multiple signaling pathways induce specific histone $\mathrm{H} 3$ modifications and early gene expression in hippocampal neurons. J Cell Sci 116:4905-4914.
Dias BG, Banerjee SB, Duman RS, Vaidya VA (2003) Differential regulation of brain derived neurotrophic factor transcripts by antidepressant treatments in the adult rat brain. Neuropharmacology 45:553-563.

D'Sa C, Duman RS (2002) Antidepressants and neuroplasticity. Bipolar Disord 4:183-194.

Duman RS, Heninger GR, Nestler EJ (1997) A molecular and cellular theory of depression. Arch Gen Psychiatry 54:597-606.

Grunstein M (1997) Histone acetylation in chromatin structure and transcription. Nature 389:349-352.

Guan Z, Giustetto M, Lomvardas S, Kim JH, Miniaci MC, Schwartz JH, Thanos D, Kandel ER (2002) Integration of long-term-memory-related synaptic plasticity involves bidirectional regulation of gene expression and chromatin structure. Cell 111:483-493.

Hiroi N, Marek GJ, Brown JR, Ye H, Saudou F, Vaidya VA, Duman RS, Greenberg ME, Nestler EJ (1998) Essential role of the fosB gene in molecular, cellular, and behavioral actions of chronic electroconvulsive seizures. J Neurosci 18:6952-6962.

Huang Y, Doherty JJ, Dingledine R (2002) Altered histone acetylation at glutamate receptor 2 and brain-derived neurotrophic factor genes is an early event triggered by status epilepticus. J Neurosci 22:8422-8428.

Jenuwein T, Allis CD (2001) Translating the histone code. Science 293:1074-1080.

Johnson KD, Bresnick EH (2002) Dissecting long-range transcriptional mechanisms by chromatin immunoprecipitation. Methods 26:27-36.

Manji HK, Drevets WC, Charney DS (2001) The cellular neurobiology of depression. Nat Med 7:541-547.

Metsis M, Timmusk T, Arenas E, Persson H (1993) Differential usage of multiple brain-derived neurotrophic factor promoters in the rat brain following neuronal activation. Proc Natl Acad Sci USA 90:8802-8806.

Morgan JI, Cohen DR, Hempstead JL, Curran T (1987) Mapping patterns of c-fos expression in the central nervous system after seizure. Science 237:192-197.

Nestler EJ, Barrot M, DiLeone RJ, Eisch AJ, Gold SJ, Monteggia LM (2002) Neurobiology of depression. Neuron 34:13-25.

Newton SS, Collier EF, Hunsberger J, Adams D, Terwilliger R, Selvanayagam E, Duman RS (2003) Gene profile of electroconvulsive seizures: induction of neurotrophic and angiogenic factors. J Neurosci 23:10841-10851.

Nibuya M, Morinobu S, Duman RS (1995) Regulation of BDNF and trkB mRNA in rat brain by chronic electroconvulsive seizure and antidepressant drug treatments. J Neurosci 15:7539-7547.

Nibuya M, Nestler EJ, Duman RS (1996) Chronic antidepressant administration increases the expression of cAMP response element binding protein (CREB) in rat hippocampus. J Neurosci 16:2365-2372.

Shirayama Y, Chen AC, Nakagawa S, Russell DS, Duman RS (2002) Brainderived neurotrophic factor produces antidepressant effects in behavioral models of depression. J Neurosci 22:3251-3261.

Tao X, Finkbeiner S, Arnold DB, Shaywitz AJ, Greenberg ME (1998) Ca2+ influx regulates $B D N F$ transcription by a $C R E B$ family transcription factor-dependent mechanism. Neuron 20:709-726.

Thome J, Sakai N, Shin K, Steffen C, Zhang YJ, Impey S, Storm D, Duman RS (2000) cAMP response element-mediated gene transcription is upregulated by chronic antidepressant treatment. J Neurosci 20:4030-4036.

Thomson S, Clayton AL, Mahadevan LC (2001) Independent dynamic regulation of histone phosphorylation and acetylation during immediateearly gene induction. Mol Cell 8:1231-1241.

Timmusk T, Palm K, Metsis M, Reintam T, Paalme V, Saarma M, Persson H (1993) Multiple promoters direct tissue-specific expression of the rat BDNF gene. Neuron 10:475-489.

Turner BM (2002) Cellular memory and the histone code. Cell 111:285-291.

Wells J, Farnham PJ (2002) Characterizing transcription factor binding sites using formaldehyde crosslinking and immunoprecipitation. Methods $26: 48-56$

West AE, Griffith EC, Greenberg ME (2002) Regulation of transcription factors by neuronal activity. Nat Rev Neurosci 3:921-931.

Winston SM, Hayward MD, Nestler EJ, Duman RS (1990) Chronic electroconvulsive seizures down-regulate expression of the immediate-early genes c-fos and c-jun in rat cerebral cortex. J Neurochem 54:1920-1925. 